\title{
Trends in erythemal doses at the Polish Polar Station, Hornsund, Svalbard based on the homogenized measurements (1996-2016) and reconstructed data (1983-1995)
}

\author{
Janusz W. Krzyścin and Piotr S. Sobolewski \\ Institute of Geophysics, Polish Academy of Sciences, Warsaw, 01-452, Poland \\ Correspondence: Janusz W. Krzyścin (jkrzys@igf.edu.pl) \\ Received: 3 July 2017 - Discussion started: 20 July 2017 \\ Revised: 17 October 2017 - Accepted: 14 November 2017 - Published: 2 January 2018
}

\begin{abstract}
Erythemal daily doses measured at the Polish Polar Station, Hornsund $\left(77^{\circ} 00^{\prime} \mathrm{N}, 15^{\circ} 33^{\prime} \mathrm{E}\right)$, for the periods 1996-2001 and 2005-2016 are homogenized using yearly calibration constants derived from the comparison of observed doses for cloudless conditions with the corresponding doses calculated by radiative transfer (RT) simulations. Modeled all-sky doses are calculated by the multiplication of cloudless RT doses by the empirical cloud modification factor dependent on the daily sunshine duration. An all-sky model is built using daily erythemal doses measured in the period 2005-2006-2007. The model is verified by comparisons with the 1996-1997-1998 and 2009-2010-2011 measured data. The daily doses since 1983 (beginning of the proxy data) are reconstructed using the all-sky model with the historical data of the column ozone from satellite measurements (SBUV merged ozone data set), the snow depth (for ground albedo estimation), and the observed daily sunshine duration at the site. Trend analyses of the monthly and yearly time series comprised of the reconstructed and observed doses do not reveal a statistically significant trend in the period 1983-2016. The trends based on the observed data only (1996-2001 and 2005-2016) show declining tendency (about $-1 \%$ per year) in the monthly mean of daily erythemal doses in May and June, and in the yearly sum of daily erythemal doses. An analysis of sources of the yearly dose variability since 1983 shows that cloud cover changes are a basic driver of the long-term UV changes at the site.
\end{abstract}

\section{Introduction}

The importance of the solar UV radiation on human health and ecosystems is widely discussed in the literature since the ozone hole discovery in the early 1980s (e.g., WMO, 2014). The Montreal Protocol was signed by UN countries in 1987 to protect the ozone layer, which acts as a shield against the solar UV. Since 1980, especially large ozone depletion was observed every year in the late winter and spring (the so-called ozone hole) over Antarctica (e.g., WMO, 2014). However, severe ozone losses appeared occasionally over the Arctic, e.g., in 2011 (Garcia, 2011; Bernhard et al., 2013) and in 2016 (http://www.ametsoc.net/sotc2016/Ch05_ Arctic.pdf). The ozone downward trend and the increase in the surface UV in the Arctic was observed in 1990s (Fioletov et al., 1997; Newmann et al., 1997; Gurney, 1998).

The amount of column ozone and its vertical distribution have been measured using a ground-based and satellite network. Nowadays, the ozone distribution over the whole globe is available for scientific purposes. The surface UV radiation in the UV-B range also depends on the Sun's elevation, cloud and aerosol characteristics, and the surface albedo, which are widely variable from site to site. There are a limited number of ground-based stations measuring erythemaly effective doses continuously for longer than 20 years. These include only five of the northernmost stations above $70^{\circ} \mathrm{N}$ : Alert $\left(82.5^{\circ} \mathrm{N}, 62.31^{\circ} \mathrm{E}\right), \mathrm{Ny}$-Ålesund $\left(78.92^{\circ} \mathrm{N}, 11.92^{\circ} \mathrm{E}\right)$, Hornsund $\left(77.0^{\circ} \mathrm{N}, 15.33^{\circ} \mathrm{E}\right)$, Resolute $\left(74.72^{\circ} \mathrm{N}, 94.98^{\circ} \mathrm{W}\right.$, and Barrow $\left(71.32^{\circ} \mathrm{N}, 156.68^{\circ} \mathrm{W}\right)$. The algorithm to calculate the surface UV using the satellite data (total ozone, groundreflectivity) over high-latitude regions sometimes failed due to the fact that the observed high-reflectivity surfaces might 
be erroneously classified as high ground albedo (from snow and ice cover) or cloud effect (Tanskanen et al., 2007). It is crucial to examine the UV variability over the Arctic regions, especially for high latitudinal coastal sites, because of rich and diverse ecosystems located in this area (Hessen et al, 2001). It is anticipated that anthropogenic climate effects will be the most pronounced in high latitudinal regions (Taalas et al., 2000; IPCC, 2014).

Maintaining homogeneity of long-term UV time series (20+ years) taken from various instruments is a challenging task, especially for remote sites. In this paper, we propose a method for the UV data homogenization applicable for any remote Arctic site like the Polish Polar Station Hornsund (Sect. 3). Next, we reconstruct the UV doses dating back to 1983 when the observations of proxies for the UV variability started at Hornsund (Sect. 4). Finally, we search for linear trends and their uncertainty using a Monte Carlo approach (Sect. 5) applied to monthly and yearly doses (Sect. 6) based on the reconstructed and observed data (1983-2016) and the observed data only (1996-2016 with the 2002-2004 gap).

\section{UV and ancillary data}

The erythemal UV measurements at Hornsund were carried out from 1996 up to 2001 by an improved version (with temperature stabilization) of the classic Robertson-Berger (RB) UV meter. This was a prototype of the presently widely used broadband Solar Light Model 500 (denoted SL 500) radiometer produced by Solar Light Co. RB meter was designed in the early 1970s to measure erythemal solar irradiation as its spectral characteristic resembled that of the human skin (McKinlay and Diffey, 1987). The prototype was designed in the Institute of Geophysics (IG), Polish Academy of Sciences (PAS), Belsk, in the late 1980s and since then was used in the UV monitoring at the Central Geophysical Laboratory, IG PAS, Belsk, Poland. It was moved to the Hornsund observatory in 1995 and put into regular UV monitoring in 1996 (Krzyścin and Sobolewski, 2001) that lasted up to autumn 2001. Since spring 2004, a new UV broadband meter Kipp \& Zonen UVS-AE-T (Fig. 1) has been installed at Hornsund and started continuous UV monitoring in April 2005. In spring 2006 and 2007, it was calibrated by the IG PAS substandard Kipp \& Zonen UVS-AE-T (no. 616), which was frequently adjusted to the Belsk's Brewer spectrophotometer (Sobolewski and Krzyścin, 2006). There were logistical difficulties with the calibration of the Hornsund meter by a higher-level standard (e.g., the Brewer spectrophotometer) as the station could only by reached by snowmobiles (in spring), helicopters, or ships (in summer). Thus, we decided to apply radiative transfer (RT) model simulations for clearsky conditions to calibrate output of the UV radiometer during cloudless days and perform a homogenization of the past UV data.

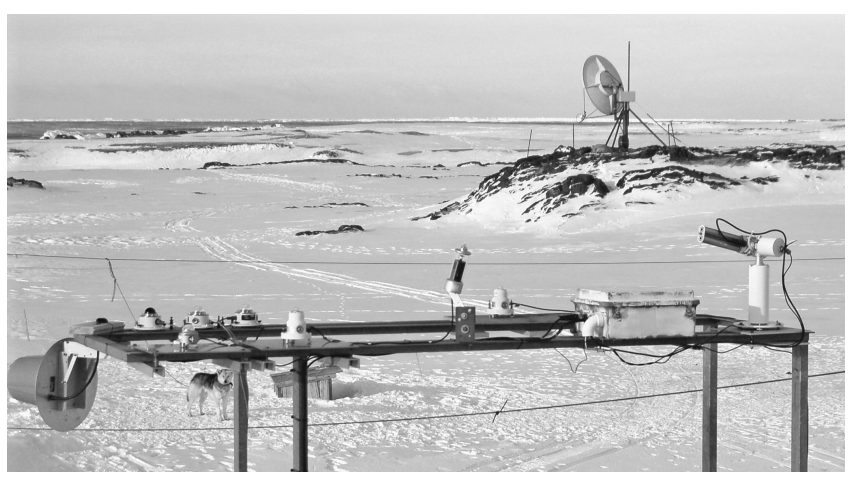

Figure 1. The observing platform at the Polish Polar Station Hornsund $\left(77^{\circ} 00^{\prime} \mathrm{N}, 15^{\circ} 33^{\prime} \mathrm{E}\right)$. Photo by P. S. Sobolewski.

The following ancillary data routinely measured at Hornsund is used in the model simulations: snow depth, aerosol characteristics (aerosol optical depth, single scattering albedo from the Cimel Sun photometer observations since 2004), and the sunshine duration (by a CampbellStokes recorder).

\section{Data homogenization}

Clear-sky conditions over the Hornsund observatory were identified by the examination of the 1 min erythemal irradiation daily pattern. The smoothness of the pattern and the steady increase (before local noon) and decrease (after local noon) of the irradiances provided a criterion for cloudless day. The Tropospheric Ultraviolet-Visible (TUV) RT model by Madronich (1993) is implemented to calculate hypothetical clear-sky daily doses for the selected cloudless days. The TUV input consists of the column ozone amount (taken from the site overpasses by the Solar Backscatter Ultraviolet (SBUV) instrument onboard the NOAA satellites and aerosol characteristics from the AERONET database. The ground albedo in UV range is approximated by a local formula:

Albedo $_{\text {GROUND }}=0.1+$ Depth $_{\text {SNOW }} / 40$,

where Depth SNOw $_{\text {is }}$ the measured snow depth in centimeters and AlbedogROUND is assumed to be equal to 0.9 for snow depth larger than $32 \mathrm{~cm}$. Equation (1) was found, experimentally, to have the best agreement with the measured daily doses in the period when the UV data at Hornsund were calibrated by the IG PAS substandard (2006-2007).

For each year (2005-2016) ratios between the modeled and observed daily doses were averaged to provide the annual correction factor, which is applied to all measured daily doses. The annual correction factor (ACF) was calculated separately for selected ranges of the noon solar zenith angle (SZA); $\mathrm{SZA} \leq 60^{\circ}, 60^{\circ}<\mathrm{SZA} \leq 70^{\circ}, 70^{\circ}<\mathrm{SZA} \leq 80^{\circ}$, and $\mathrm{SZA}>80^{\circ}$, in the period March-June when many 


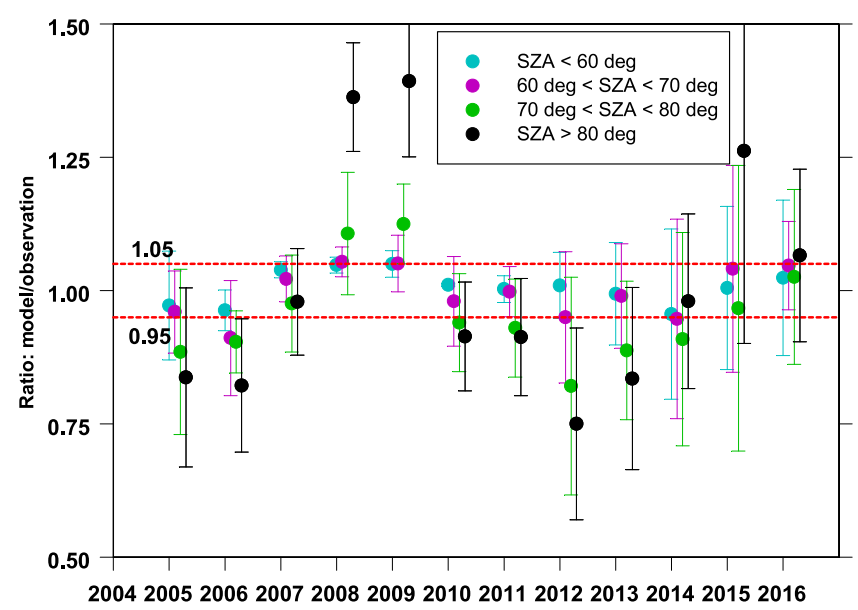

Figure 2. The calibration constants for the Kipp \& Zonen UVS-AE$\mathrm{T}$ instrument in the period 2005-2016 derived from a comparison of the modeled clear-sky doses with the observed ones in cloudless conditions for four solar zenith angle (SZA) ranges.

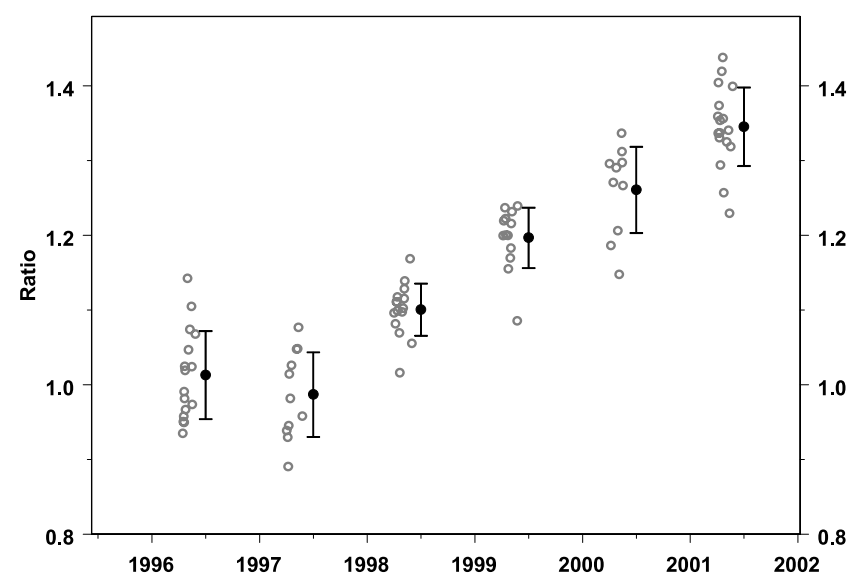

Figure 3. The calibration constants for the prototype of the Solar Light instrument in the period 1996-2001 derived from a comparison of the modeled clear-sky doses, assuming fixed aerosol optical depth $(0.16$ at $340 \mathrm{~nm})$ with the observed ones in cloudless conditions in the March-June period. Full circles and bars represent the mean value and \pm 1 standard deviation range in the selected year.

cloudless days were found. Figure 2 shows ACF time series (2005-2016) for four SZA ranges. It is worth noting that ACF oscillates in the range $0.95-1.05$ for $\mathrm{SZA} \leq 60^{\circ}$, $60^{\circ}<\mathrm{SZA} \leq 70^{\circ}$. There is a much larger ACF variability of $\sim 0.75-1.35$ for noon SZA $>80^{\circ}$ (early March), i.e., for a period with a weak UV intensity when the solar UV is dominated by the diffusive component related to aerosol characteristics, which is sometimes not well parameterized in the RT model. All time series shown in Fig. 2 are trendless. It seems that the instrument sensitivity to the UV radiation is constant since 2005 , i.e., there is no need to use any correction for the instrument aging and $\mathrm{ACF}=1$.

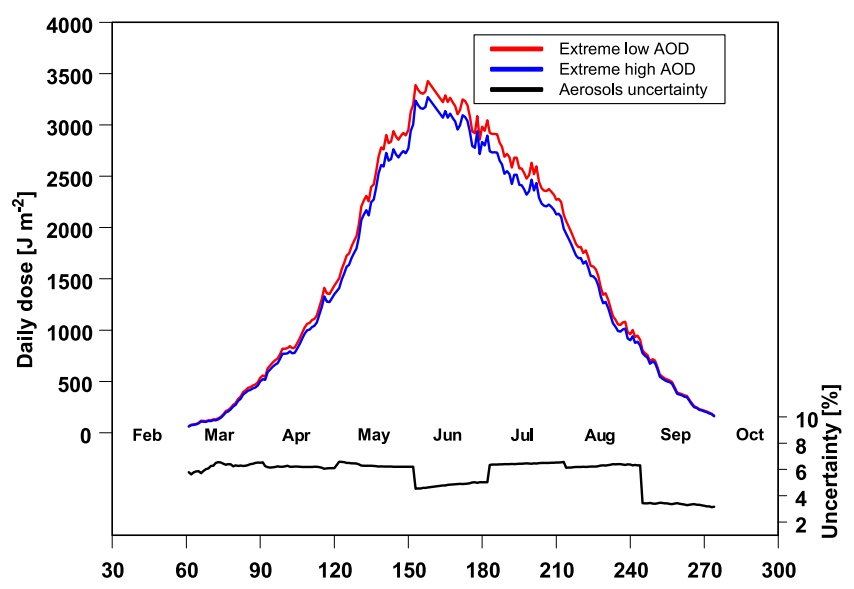

Figure 4. Radiative model simulations of daily erythemal doses for clear-sky conditions in 1996 using observed total ozone, surface albedo, and extreme high and low monthly aerosol optical thickness derived from all CIMEL Sun photometer measurements at Hornsund in the period 2004-2016. Uncertainty is calculated as the difference between the extreme daily doses expressed in percentage of the mean daily dose.

The same procedure was used for the first period (19962001) of the UV monitoring at Hornsund but constant aerosols of aerosol optical depth (AOD) at $340 \mathrm{~nm}$ equal to 0.16 was assumed. During that period there were no Cimel Sun photometer observations. Thus, for the 1996-2001 calibration, we select AOD value representing the mean AOD value found for the period 2004-2016. Moreover, only one ACF value was calculated regardless of SZA. Figure 3 shows yearly ACF values for the period 1996-2001. It is seen that almost linear instrument deterioration of $\sim 10 \%$ per year appeared after 2 years (1996-1997) of its stable behavior. The prototype instrument operated without any maintenance since 1997. Thus, it seems that the instrumental drift appeared due to increasing humidity level inside the instrument. The following ACF values, which were derived from model-observation comparisons for clear-sky days, are applied to the observed (uncorrected) daily doses: 1.01 (1996), 0.99 (1997), 1.10 (1998), 1.20 (1999), 1.26 (2000), and 1.35 (2001).

The uncertainty of UV observations by the prototype instrument induced by unknown aerosol AOD in ACF calculations could be estimated using extreme AOD monthly values in RT simulations, i.e., 2.5 and 97.5 percentiles of AOD values taken from all Cimel measurements in a selected month for the period 2004-2016. Figure 4 shows the differences between clear-sky erythemal daily doses calculated in 1996 for extreme high ( 2.5 percentile) and extreme low (97.5 percentile) AOD monthly values. Actual snow cover and satellite total ozone were used in these simulations. Because the AOD variability range depends on the month, we found that the uncertainty level varies between 2 and $7 \%$. Further in 
calculations we select $7 \%$ as a characteristic of the instrument's uncertainty induced by a lack of precise information on aerosol loading in ACF calculations for the period 19962001.

\section{Data reconstruction}

Past variations of the surface erythemal radiation in periods without UV measurements could be retrieved from statistical and radiative transfer modelling using various proxies to describe attenuation of UV radiation in the atmosphere (e.g., Lindfors and Vuilleumier, 2005; Koepke et al., 2006; Lindfors et al., 2007; Rieder et al., 2008). Global solar radiation, cloud cover, solar zenith angle, and the sunshine duration were usually used as proxies to construct empirical formulas to determine cloud attenuation of UV radiation. Junk et al. (2007) applied an advanced statistical technique, artificial neural network, to find out the most effective combination of proxies for surface UV estimation. It appeared that global solar radiation, solar zenith angles, and the diffusive part of global solar radiation were essential proxies for UV reconstruction giving $1-2 \%$ bias and $\sim 3-4 \%$ root mean square (RMS) error relative to the measured daily erythemal dose. Bilbao et al. (2011) found an RMS error of 4-9\% when only global solar irradiance and SZA were used to parameterize $10 \mathrm{~min}$ erythemal doses. For some sites, only the sunshine duration was possible as a cloud attenuation proxy and it yielded 5-6\% bias and RMS errors of order $20 \%$ for the reconstructed daily doses (Lindfors and Vuilleumier, 2005).

Here reconstruction of the erythemal daily doses is derived using hypothetical clear-sky erythemal daily doses from a radiative transfer model simulation using the following input parameters: total ozone (for satellite overpasses), albedo (retrieved from snow depth), and aerosol optical depth at $340 \mathrm{~nm}$ (from collocated CIMEL Sun photometer measurements). The attenuation due to clouds is derived from an empirical formula based on the daily sunshine duration measured by a Campbell-Stokes recorder. The model's regression parameters were determined using the 2005-2006-2007 daily erythemal doses (by Kipp \& Zonen UV radiometer). The model is verified using the 1996-1997-1999 (output of SL 500 prototype) and 2009-2010-2011 (output of Kipp \& Zonen UV radiometer) data.

A semiempirical model is built to reproduce the measured daily doses (erythemal $\mathrm{J} \mathrm{m}^{-2}$ ) for the period 2006-20072008:

$\operatorname{DOSE}_{\mathrm{MOD}}(t)=\mathrm{CMF}(t) \times \operatorname{DOSE}_{\mathrm{CLEAR}-\operatorname{SKY}}(t)$,

where DOSE $\mathrm{CLEAR}_{\text {-SKY }}(t)$ is a hypothetical clear-sky daily dose in day $t$ from the radiative transfer model simulations (TUV) with the following input:

- the daily total ozone $\left(\mathrm{TO}_{3}\right)$ from the station satellite overpasses (SBUV merged data set)
- the snow albedo according to Eq. (1) with the snow depth from the station meteorological data

- daily observed aerosol optical depth (AOD) at $340 \mathrm{~nm}$ by the collocated Cimel Sun photometer or AOD equal to 0.16 , i.e., equal to long-term (2004-2016) monthly means of AOD at $340 \mathrm{~nm}$, for days without CIMEL measurements.

CMF is an empirical cloud modification factor used to parameterize an attenuation of hypothetical clear-sky daily doses by clouds. We have no variability of the sunshine duration throughout a day. Using the daily values adds additional uncertainties to modeled values as a duration of clearsky conditions near local noon is decisive for daily doses.

Finally, the relative sunshine duration (in percent of the polar day duration), SUN_DUR( $(t)$, was selected as single UV regressor, and the following formula was obtained by standard least-squares approach:

$\mathrm{CMF}(t)=1.0324\left[\operatorname{SUN} \_\operatorname{DUR}(t)\right]^{0.1951}$.

The regression coefficients $(1.0324,0.1951)$ are found to be highly statistically significant at the $99 \%$ confidence level. Model (3) explains $\sim 45 \%$ of CMF variance. Table 1 shows the monthly bias and RMS errors of the model (3) performance for March-September in the period 2005-2016. The model setup is similar to that used by Lindfors et al. (2003) for UV daily-dose reconstruction for Sodankylä. However, our model provides RMS error $\sim 15 \%$ for estimates of the daily erythemal dose. Lindfors et al. (2003) found RMS error of $\sim 23 \%$.

To determine how model (2) uncertainty influences trend estimates for the whole period 1983-2016, we propose a Monte Carlo methodology to derive the trend value and its uncertainty based on a hypothetical bootstrap sample $(N=10000)$ of the linear trend coefficients and their errors (see Sect. 5).

Model (2) with CMF defined by Eq. (3) performs almost perfectly (see Fig. 5a). The model-observation correlation coefficients exceed 0.9 and the smoothed pattern of scattered data obtained by LOWESS (locally weighted scatter plot smoothing, Cleveland, 1979) matches the 1-1 line (perfect agreement line - diagonal of the square). Slope by an ordinary least-squares fit is $0.99 \pm 0.02(1 \sigma)$, i.e., it also supports a perfect correspondence between measured and modeled daily doses.

The regression coefficient of model (2) was computed using the multilinear least-squares fit to the observed 20052006-2007 daily doses. Comparisons of the modeled data to the observed ones taken in different periods will provide a kind of model verification and will support the accuracy of the calibration constants applied to total UV data (Sect. 3). Figure 5b and c show the comparisons for the period 20092010-2011 and 1996-1997-1998, respectively. The modelobservation correlation coefficients are high $(\sim 0.95)$, with 

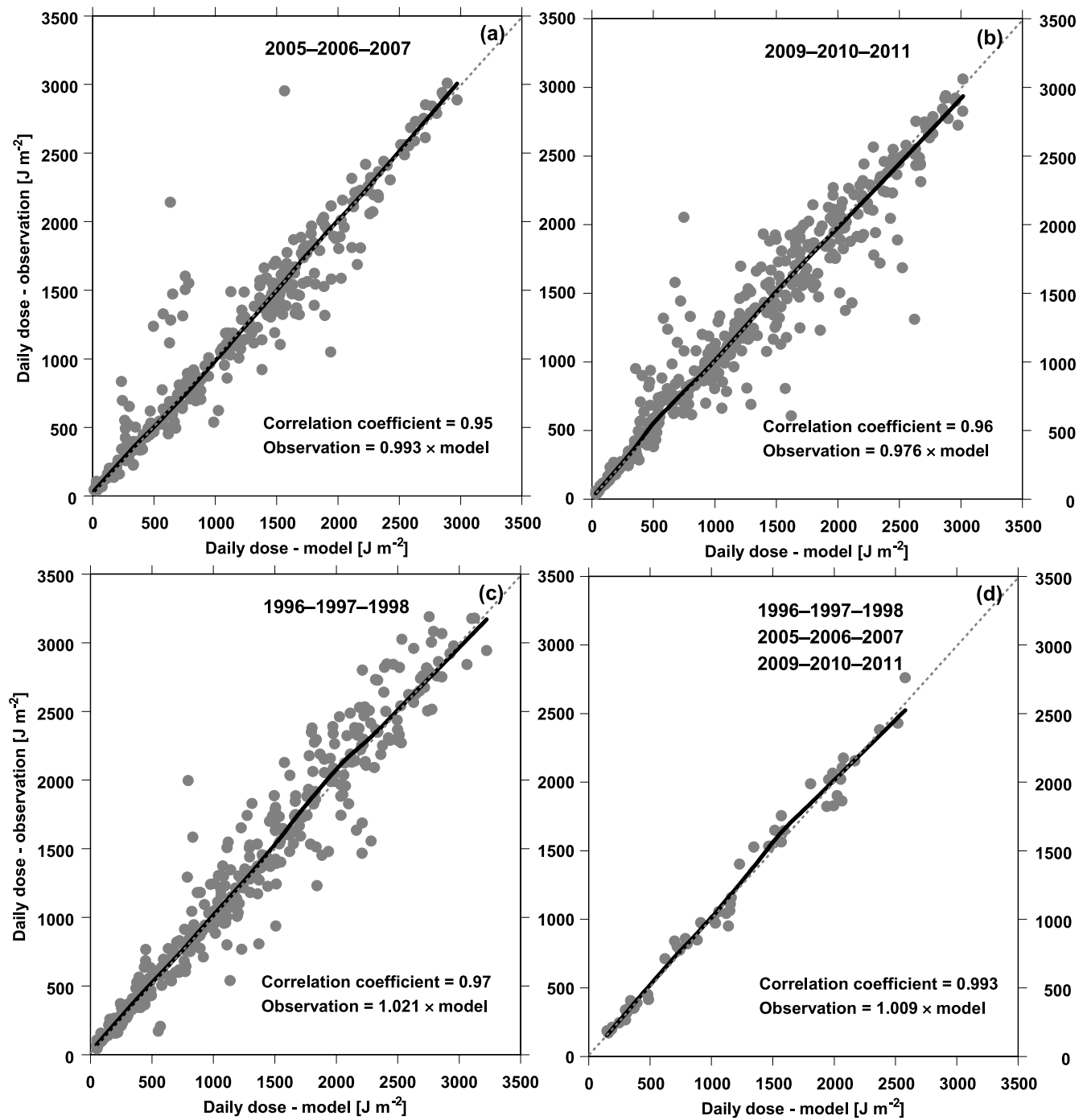

Figure 5. The observed versus modeled erythemal doses: (a) daily doses for the period 2005-2006-2007, (b) daily doses for the period 2009-2010-2011, (c) daily doses for the period 1996-1997-1998 and (d) monthly mean daily doses for the periods 1996-1997-1998, 2005-2006-2007, and 2009-2010-2011.

Table 1. Monthly mean of the daily erythemal doses, participation of the monthly sum of daily doses in the yearly (February-October) sum of the daily doses, monthly mean difference between the observed and modeled doses, and corresponding root mean square error (RMSE), monthly mean difference between the observed and modeled doses as a percent of the observed doses, and corresponding RMSE. The results are from modeled and observed daily doses at Hornsund for the period 2005-2016.

\begin{tabular}{|c|c|c|c|c|c|c|}
\hline \multirow[t]{2}{*}{ Month } & \multirow[t]{2}{*}{$\operatorname{Mean}\left(\mathrm{J} \mathrm{m}^{-2}\right)$} & \multirow[t]{2}{*}{$\%$ of yearly dose } & \multicolumn{2}{|c|}{$($ Obs. - model $)\left(\mathrm{J} \mathrm{m}^{-2}\right)$} & \multicolumn{2}{|c|}{$($ Obs.-model)/Obs (\%) } \\
\hline & & & \multicolumn{2}{|c|}{ Bias RMSE } & \multicolumn{2}{|c|}{ Bias RMSE } \\
\hline March & 178 & 3 & 17 & 22 & 9 & 14 \\
\hline April & 744 & 10 & 39 & 84 & 6 & 14 \\
\hline May & 1516 & 21 & 68 & 214 & 4 & 14 \\
\hline June & 1983 & 27 & -6 & 237 & -0 & 14 \\
\hline July & 1627 & 23 & -89 & 211 & -5 & 15 \\
\hline August & 876 & 12 & -44 & 116 & -5 & 14 \\
\hline September & 266 & 4 & -3 & 46 & -1 & 15 \\
\hline
\end{tabular}


linear slopes close to 1 . Moreover, the smoothed patterns of scattered data points match the 1-1 line (perfect agreement line) throughout the whole range of the data variability.

The model-observation agreement appears to be even better for the monthly averages of daily erythemal doses (Fig. 5d) for three periods together: 1996-1997-1998, 20052006-2007, and 2009-2010-2011. Here the correlation coefficient is equal to $\sim 0.99$ and the linear regression line has the slope of $1.002+0.009(1 \sigma)$. The simple parameterization of cloud effects on the surface erythemal dose by Eq. (3) could be used for a reconstruction of the long-term UV variability at Hornsund. Moreover, almost the same model performance was found for the periods with the UV observations done by different instruments: 1996-1997-1998 (SL 500 prototype), 2005-2006-2007 (model's built period), and 20092010-2011 (Kipp \& Zonen UVS-AE-T radiometer). It supports the data homogeneity of the UV observations by different UV radiometers since 1996.

\section{Monte Carlo method for trend estimates}

We propose a Monte Carlo procedure to estimate a linear trend that accounts for various uncertainties of the daily doses throughout the examined period. The monthly and yearly trend values and their significance are derived averaging linear regression coefficients and their errors taken from a standard least-squares linear regression applied to a large number $(N=10000)$ of hypothetical erythemal UV time series. These time series were randomly generated for the period 1983-2016. Random representatives are generated, taking into account specific uncertainty of the UV data for selected periods with different data categories, as follows.

- For the periods 1983-1995 and 2001-2004, we use the reconstructed data, based on model (2), adjusted for the model (2) uncertainty, DOSEMOD, Adjusted, $n(t)$. To the modeled value by Eq. (2) we add a random component, $\mathrm{RAN}_{n}($ Mean $(t), \mathrm{SD}(t))$, being the $n$th value taken from normal distribution with mean value, $\operatorname{Mean}(t)$, and standard deviations $\mathrm{SD}(t)$, which allows for possible variations of the hypothetical daily dose around its original value to be accounted for:

$$
\begin{aligned}
& \operatorname{DOSE}_{\mathrm{MOD}, \text { Adjusted, } n}(t)=\mathrm{DOSE}_{\mathrm{MOD}}(t)+\mathrm{RAN}_{n} \\
& (\mathrm{Mean}(t), \mathrm{SD}(t)), n=(1, \ldots, N=10000),
\end{aligned}
$$

where Mean $(t)$ and $\operatorname{SD}(t)$ are monthly mean value and pertaining standard deviation calculated from differences between the measured daily doses, $\operatorname{DOSE}_{\mathrm{OBS}}(t)$, in the period 2005-2016, and modeled doses, $\operatorname{DOSE}_{\mathrm{MOD}}(t)$, for the calendar month corresponding to $t$ value (see Table 1).

- For the period 1996-2001 and 2005-2016 we use the Monte Carlo set of the potential representatives of the observed time series that is also adjusted for the observation uncertainty, DOSE $\mathrm{OBS}$ Adjusted, $n(t)$. In the former period, the data uncertainty was larger than that in the latter period because of using a noncommercial instrument and less precise ACF calculation to account for the instrument deterioration.

$$
\begin{aligned}
& \text { DOSE}_{\mathrm{OBS}} \text {, Adjusted, } n \\
& \left(0, \mathrm{SD}_{k}\right), k=(1,2), n=(1, \ldots, N=10000),
\end{aligned}
$$

where $\mathrm{SD}_{1}$ and $\mathrm{SD}_{2}$ are the 1-sigma uncertainties of the daily erythemal UV measurements in the period 1996-2001 and 2005-2016, respectively. We assume that our SL prototype had an uncertainty level similar to the commercial SL UV radiometer. Hülsen and Grobner (2007) found 11.2 and $7.2 \%$ uncertainty (at 2-sigma level) for typical SL and KZ instruments, respectively. Finally, the uncertainty of UV daily doses by the SL prototype is calculated as $13.2 \%$, taking into account $7 \%$ uncertainty induced by an assumption of a constant AOD value in the ACF calculation for the period 19962001 (Sect. 3).

In total, 10000 hypothetical representatives of daily erythemal doses values for each day in the March-September subperiod of the period 1983-2016 were generated. Next, these daily doses were averaged to produce the monthly mean of daily doses and a standard least-squares linear fit was applied to each hypothetical monthly series to obtain a linear slope and its standard error. To check a hypothesis of statistical significance of the trend value at 2-sigma confidence level, we calculate a number of cases with the absolute value of the slope larger than twice the standard error of the pertaining slope. The trend is statistically significant at 2-sigma level if at least $95 \%$ of slopes fulfil this condition. The number of Monte Carlo time series was determined by testing the stability of the mean slope and its 2-sigma slope error when changing number of series between 1000 and 15000 . A number larger than about 10000 did not introduce any further changes in the statistical characteristics of the slope sample. Thus $N=10000$ samples are selected for further statistical analyses.

\section{Results}

Monthly means of daily erythemal doses show significant intrayear variability (Table 1), with a late spring-early summer maximum. Therefore, to compare trend values in selected months, the trend analyses are applied to percentage differences of the monthly mean of daily doses from the longterm monthly mean (2005-2016). The yearly sum of erythemal doses are calculated as a sum of the daily doses between 1 March and 30 September as earlier, and later doses are small or zero because of high solar zenith angles and polar night (between 29 October and 11 February). Similarly, to the monthly means of daily doses, the yearly sum is 


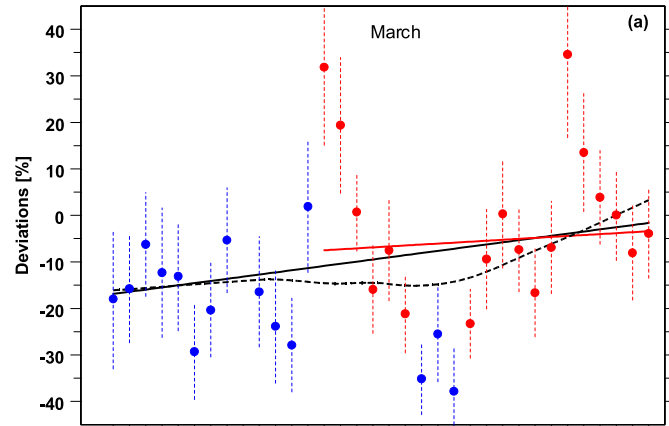

19831986198919921995199820012004200720102013201

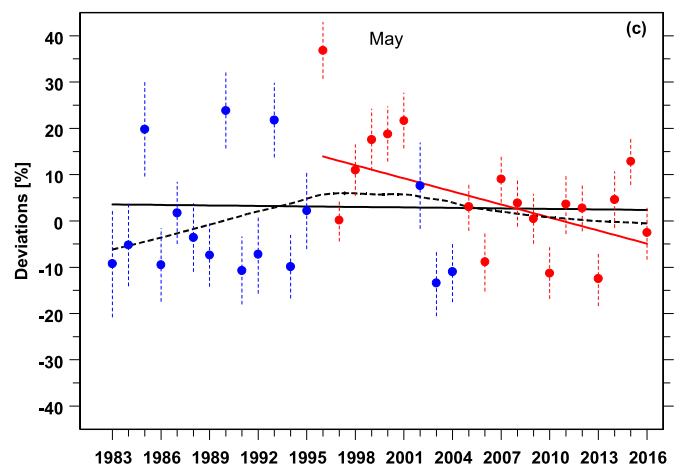

198319861989199219951998200120042007201020132016

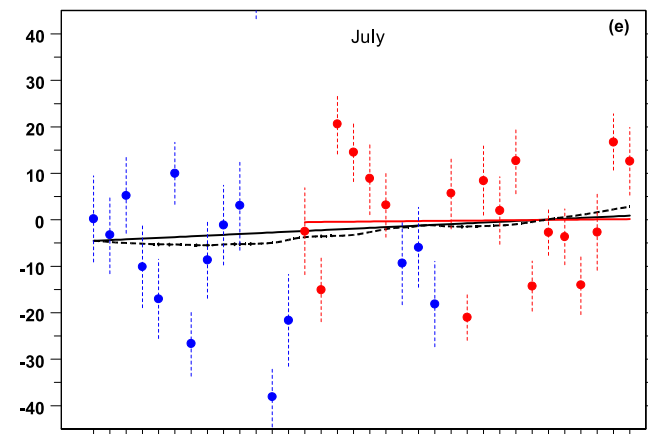

19831986198919921995199820012004200720102013201

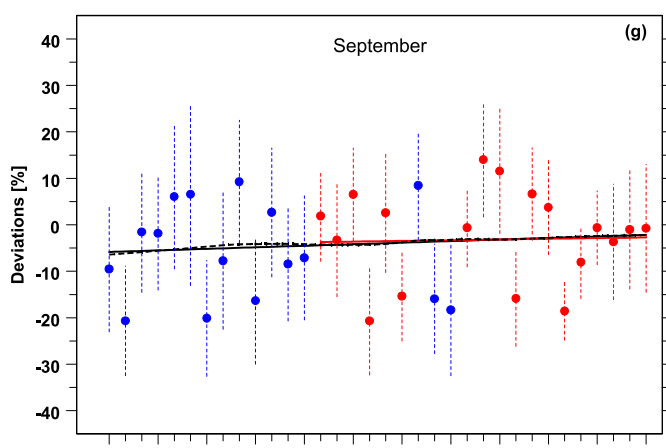

198319861989199219951998200120042007201020132016

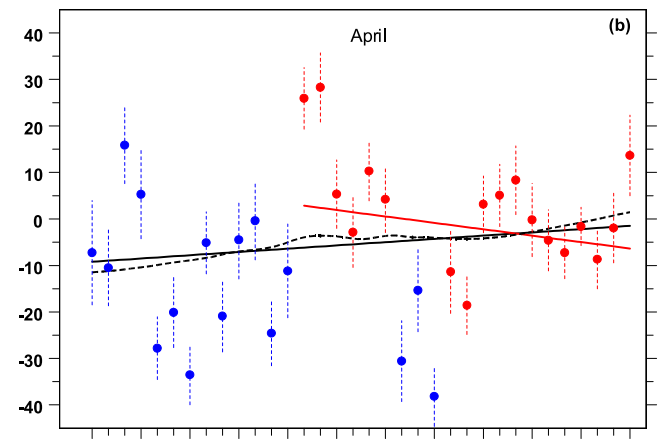

198319861989199219951998200120042007201020132016

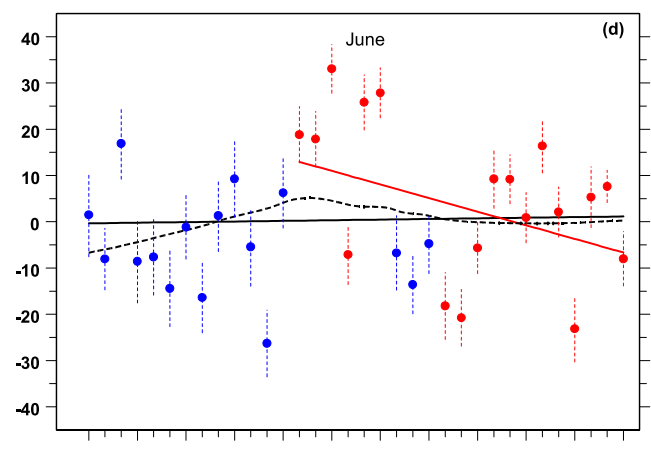

198319861989199219951998200120042007201020132016

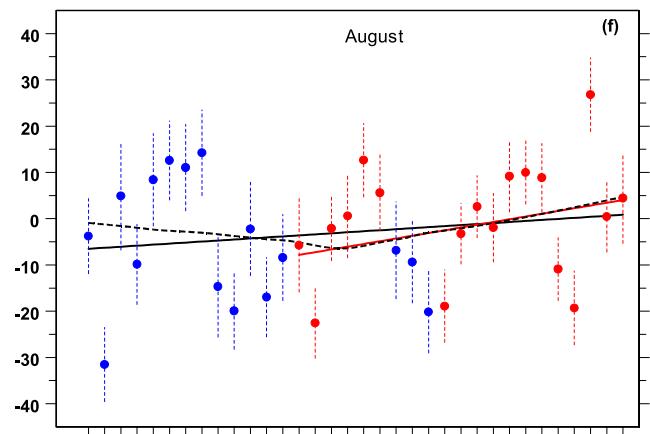

198319861989199219951998200120042007201020132016

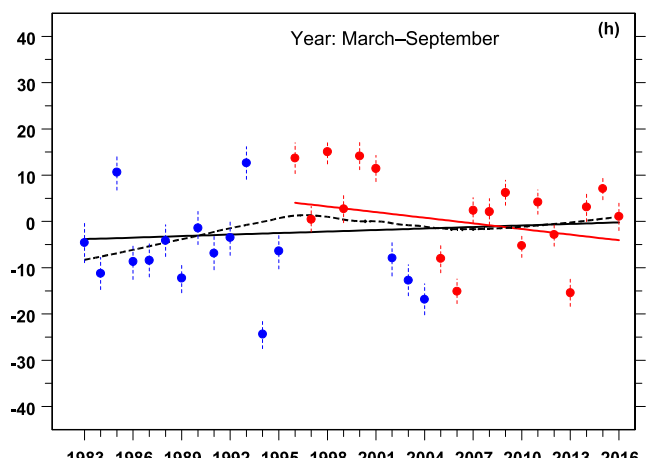

Figure 6. Time series of normalized deviations of monthly means of daily doses and normalized yearly sum of daily doses: observed values (red circles) and reconstructed values (blue circles). Vertical lines show \pm 1 standard deviation. Straight lines represent linear regression line. Dashed curves represent smoothed values by LOWES smoother (Cleveland, 1979).

converted to the normalized departures relative to the mean yearly sum in the period 2005-2016.
Figure 6 illustrates the time series of the monthly (MarchSeptember) and yearly normalized departures from the longterm (2005-2016) monthly means and a yearly sum of daily 
doses. The regression lines show the long-term tendency in the 1983-2016 period and in the shorter period (1996-2001 and 2005-2016) when only the results of measurements were taken into account.

There are large year-to-year fluctuations in the monthly fractional deviations in the range between -40 and $40 \%$. The linear fit to the normalized departures in the 1983-2016 period reveals a slightly increasing tendency in the yearly sums and in all examined monthly means (excluding May with trendless behavior). The observed data for the 19962001 and 2005-2016 periods show a declining tendency in April, May, June, and throughout the whole year but an increasing tendency in March, August, and September. Statistical significance of the trend results is shown in Table 2.

Table 2 presents statistical characteristics of the Monte Carlo trend estimates. The mean linear trend coefficients and their mean standard errors together with pertaining range of estimates (between minimum and maximum of the slope and standard deviation) were derived by examining all slopes and their errors obtained by an ordinary least-squares fit to each Monte Carlo representative of the original time series. The trends are calculated for the period 1983-2016 (both observed and reconstructed data), for the period 1996-2016 (with observed data for the 1996-2001 and 2005-2016 periods, and the reconstructed one for the period 2002-2004), and for the period with the UV measurements only (with the gap for the period 2002-2004). The statistically significant decline at $2 \sigma$ level of about $-1 \% \mathrm{yr}^{-1}$ is revealed in May, June, and in the yearly sum for the observed 1996-2016 data (with the 2002-2004 gap). The trend analyses applied to the combined observed (1996-2001 and 2005-2016) and reconstructed data (2002-2004) show statistically significant decline only in May of $\sim-1 \% \mathrm{yr}^{-1}$.

To find sources of the long-term UV variability at Hornsund, we also analyze time series of yearly (MarchSeptember) sums of hypothetical clear-sky daily doses by RT simulations (using total ozone, aerosols, and snow albedo as model input) and the pertaining yearly cloud modification factor (i.e., actual yearly sum divided by the corresponding clear-sky value). Figure 7 a shows the yearly sum of daily doses values, for clear-sky and all-sky conditions $\left(\mathrm{kJ} \mathrm{m}^{-2}\right)$, and CMF (dimensionless). Figure $7 \mathrm{~b}$ illustrates the long-term variability of the normalized departures (percentage of the long-term mean values for the period 2005-2015). An approximate $10 \%$ increase in the yearly sum of all-sky daily erythemal doses and a slight decline in the clear-sky yearly sums due to the combined total ozone and albedo changes could be found in the 1980s and 1990s. Thus, it could be estimated that increasing cloud transparency and/or declining cloud cover should force a $\sim 10 \%$ increase in yearly sums. The clear-sky UV forcing at Hornsund appears weak in the 21 st century and UV mostly follows changes in cloud characteristics.
Table 2. The monthly and yearly mean slope of the linear fit and the corresponding standard deviation (in percentage per year) from 10000 samples of the hypothetical time series for the periods 19832016 (modeled and observed data) and 1996-2016 (observed and modeled data), and for the periods 1996-2001 and 2005-2016 (observed data only). The minimum and maximum values of the slope and its standard deviation selected from 10000 simulations are in the parentheses. Numbers in bold font represent statistically significant estimates at $2 \sigma$ level.

\begin{tabular}{|c|c|c|}
\hline Month & Slope $\left(\% \mathrm{yr}^{-1}\right)$ & $\mathrm{SD}$ error $\left(\% \mathrm{yr}^{-1}\right)$ \\
\hline \multicolumn{3}{|c|}{ 1983-2016 (modeled and observed) } \\
\hline March & $0.46(0.31,0.61)$ & $0.29(0.27,0.32)$ \\
\hline April & $0.23(0.12,0.37)$ & $0.28(0.26,0.30)$ \\
\hline May & $-0.04(-0.19,0.09)$ & $0.23(0.20,0.27)$ \\
\hline June & $0.05(-0.08,0.17)$ & $0.27(0.24,0.29)$ \\
\hline July & $0.16(0.05,0.29)$ & $0.29(0.24,0.31)$ \\
\hline August & $0.22(0.10,0.35)$ & $0.23(0.21,0.25)$ \\
\hline September & $0.11(-0.03,0.27)$ & $0.19(0.16,0.22)$ \\
\hline Year (III-IX) & $0.11(0.05,0.17)$ & $0.18(0.17,0.19)$ \\
\hline \multicolumn{3}{|c|}{ 1996-2016 (modeled and observed) } \\
\hline March & $0.20(0.00,0.37)$ & $0.71(0.64,0.77)$ \\
\hline April & $-0.46(-0.63,-0.29)$ & $0.58(0.52,0.64)$ \\
\hline May & $-\mathbf{0 . 9 4}(-1.10,-0.75)$ & $0.42(0.37,0.48)$ \\
\hline June & $-0.98(-1.17,-0.81)$ & $0.56(0.50,0.61)$ \\
\hline July & $0.03(-0.15,0.22)$ & $0.45(0.41,0.49)$ \\
\hline August & $0.59(0.45,0.74)$ & $0.44(0.40,0.49)$ \\
\hline September & $0.05(-0.17,0.22)$ & $0.40(0.33,0.46)$ \\
\hline Year (III-IX) & $0.40(-0.48,-0.33)$ & $0.35(0.33,0.38)$ \\
\hline \multicolumn{3}{|c|}{ 1996-2001 and 2005-2016 (observed) } \\
\hline March & $-0.17(-0.37,-0.00)$ & $0.64(0.57,0.75)$ \\
\hline April & $-0.82(-0.98,-0.64)$ & $0.47(0.43,0.51)$ \\
\hline May & $-\mathbf{1 . 1 0}(-1.28,-0.92)$ & $0.38(0.34,0.43)$ \\
\hline June & $-\mathbf{1 . 2 2}(-1.41,-1.02)$ & $0.50(0.45,0.55)$ \\
\hline July & $-0.78(-1.11,-0.38)$ & $0.56(0.47,0.71)$ \\
\hline August & $0.48(0.33,0.61)$ & $0.44(0.39,0.47)$ \\
\hline September & $0.11(-0.07,0.28)$ & $0.42(0.37,0.46)$ \\
\hline Year (III-IX) & $-\mathbf{0 . 7 5}(-0.85,-0.65)$ & $0.32(0.30,0.36)$ \\
\hline
\end{tabular}

\section{Discussion and conclusions}

A procedure for the examination of the UV data homogeneity is proposed based on RT simulations for clear-sky conditions. It allows the introduction of the yearly calibration coefficient showing the instrument sensitivity loss (19962001) and stable behavior in the period of measurements by the Kipp \& Zonen UVS-AE-T instrument (2005-2016). For all-sky conditions, the regression model is built using 3year data (2005-2006-2007), and comparisons of the modeled data with earlier (1996-1997-1998) and later (20092010-2011) data show the same model performance as for the model building period that supports the data homogeneity and its usefulness for the long-term trend analysis. The re- 


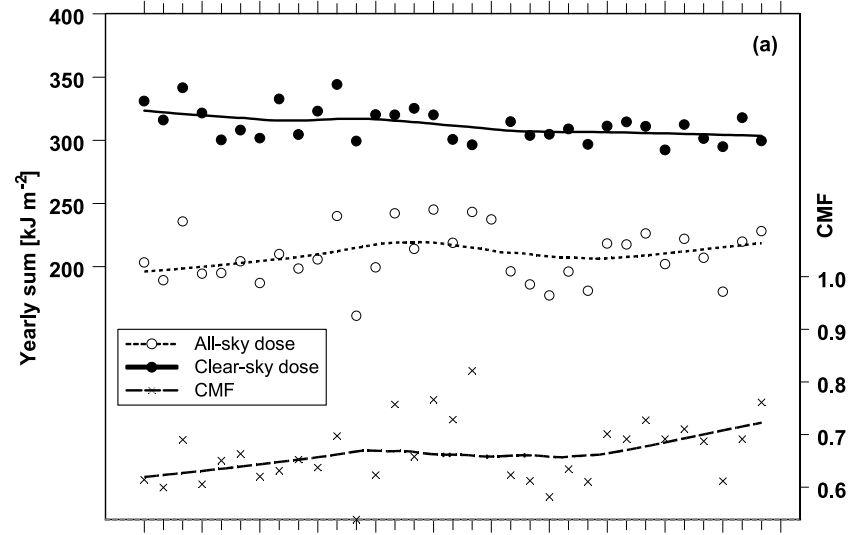

198319861989199219951998200120042007201020132016

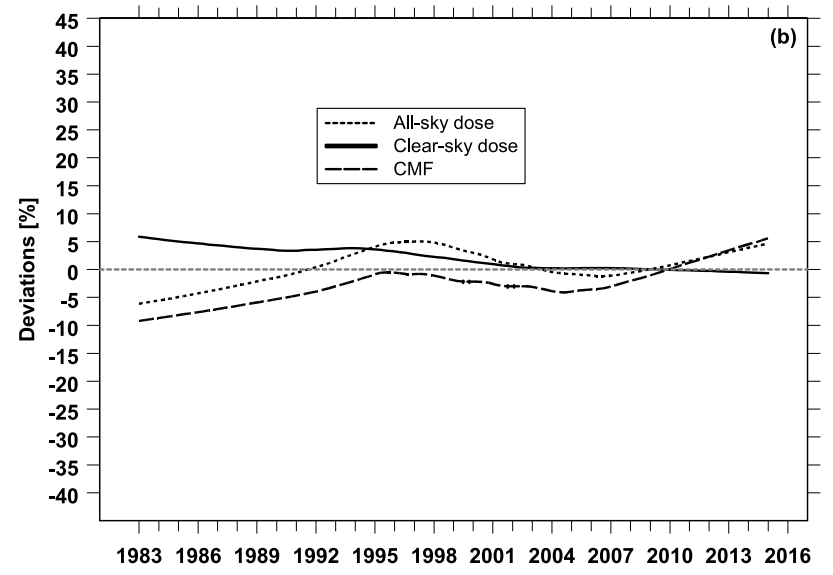

Figure 7. (a) Yearly (March-September) daily sum of erythemal doses in the period 1983-2016: modeled clear-sky values (full circles), observed and modeled all-sky values (open circles), and cloud modification factor (CMF, crosses). (b) Normalized smoothed deviations (by LOWES smoother, Cleveland, 1979) of the yearly values shown in Fig. 7a.

gression model allows the reconstruction of UV doses since 1983 , i.e., in the period when the daily total ozone (from the satellite observations) and the sunshine duration data, which represented a proxy for the cloud effects on surface UV, were both available. The reconstruction model is also used to fill the data gaps in the UV observing period (since 1996).

Previous studies showed that the sunshine duration was a worse proxy for a parameterization of the cloud attenuation when compared to the global solar radiation. Using global solar irradiance is more appropriate to parameterize cloud effects on UV (Koepke et al., 2006). However, this variable was measured at Hornsund in some disjointed periods since 1983 but the pyranometer data were not calibrated by a higherranking instrument. Sunshine duration measurements by a Campbell-Stokes instrument seem to be less influenced by deterioration of the instrument's sensitivity, and its calibration is very simple, as during cloudless conditions the sunburn track on a recorded cart should appear throughout the whole day.

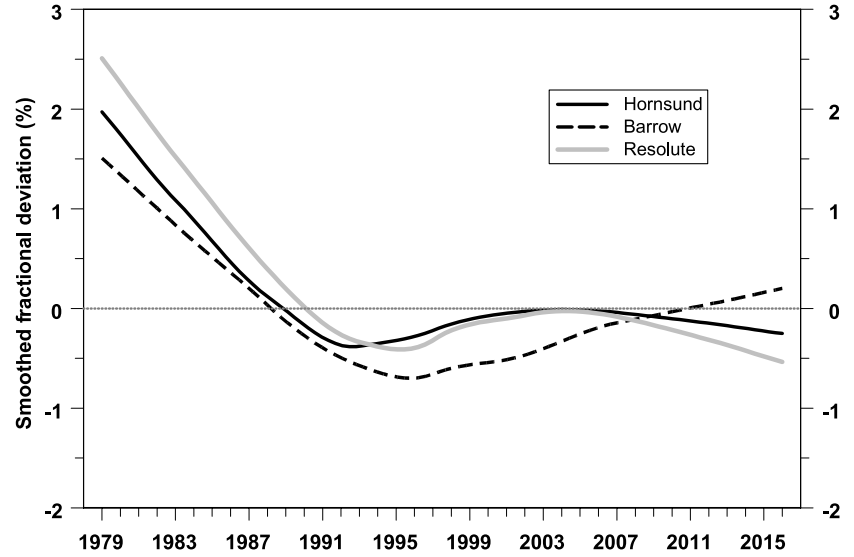

Figure 8. Smoothed time series (by LOWES smoother, Cleveland, 1979) of annual fractional deviations of mean total ozone in the May-August periods for the period 1979-2016 at Hornsund (Svalbard, Norway), Barrow (Alaska, United States), and Resolute (Cornwallis Island, Canada).

Analyses of the yearly sums of daily erythemal doses at Hornsund reveal a nonstatistically significant trend in the period 1983-2016. Two phases of the long-term behavior of total yearly doses could be identified, i.e., a positive tendency in total yearly doses in the period 1983-2000 and afterward a leveling off. The linear trend calculation by a standard least-squares fit applied to the measured (1996-2016 with the 2002-2004 gap) data shows a statistically significant declining tendency in monthly means of daily doses (May and June) and in the yearly sum of the erythemal doses. However, such a declining tendency is forced by $2-3$ years of high positive fractional deviations of the erythemal doses around 2000. Longer time series (since 1983) do not show any sign of the declining tendency starting around 1996. Bernhard et al. (2011) analysis of the monthly trends at Barrow (Alaska) for the period 1990-2010 revealed a statistically significant trend only in October (decline of about $-1 \%$ per year) when the UV intensity was rather weak without the erythemal risk.

The stratospheric ozone changes appear as a less important driver of the UV long-term variability in the whole analyzed period. Figure 8 shows the long-term (1979-2016) pattern of the total ozone mean (using SBUV merged data) for the period May-August at Hornsund, Barrow, and Resolute, i.e., in the part of the year with naturally high UV radiation $(\sim 80 \%$ of total the yearly sum). The ozone forcing on the surface UV at these sites appears to be weak (within the $\pm 1 \%$ range) from 1983 onwards (i.e., since the beginning of the reconstructed data). Cloud effects are the basic source of the UV variability at Hornsund. The albedo variations are also important as a $\sim 5 \%$ decline in the clear-sky modeled values in the 1980s and 1990s (Fig. 7b), i.e., during the ozone declining period, seems to be forced by declining snow albedo.

It seems that excessive UV radiation over the Arctic will be unlikely during the 21 st century as a prolonged decrease 
in ozone will not be possible due to the declining tendency in the concentration of the ozone-depleting chemicals in the stratosphere and anticipated intensification of the BrewerDobson circulation loading a higher amount of ozone into the Arctic stratosphere (WMO, 2014). The downward UV tendency in the Arctic will also be induced by the increase in the cloudiness, and lowering of the ground albedo due to the snow and sea-ice melting (e.g., Bais et al., 2015).

A continuation of UV measurements at Hornsund seems to be necessary as it is located in a region vulnerable to climate changes with the local climate strongly dependent on the heat arriving with the Gulf Stream. A projection of the weakening of the Atlantic meridional overturning circulation (Boulton et al., 2014) will lead to the surface cooling at the location. The possibility can not be excluded that high-reflectivity areas (sea-ice and snow) will extend over west Svalbard and the present climatic contrast between the west (warm) and east (cold) part of Svalbard will disappear. Any projection for erythemal irradiance by the end of the 21 st century is the most uncertain for this part of the Arctic.

Data availability. The total ozone overpass data were acquired from the data archive of SBUV merged ozone at ftp://toms.gsfc. nasa.gov/pub/sbuv/MERGED/. The sunshine duration and snow height data at Hornsund were available at https:/github.com/ AtmosIGFPAN/Hornsund_Data. Aerosol optical properties were taken from AERONET database at https://aeronet.gsfc.nasa.gov/ new_web/aerosols.html. Finally, the reconstructed and observed erythemal doses at Hornsund for the period 1983-2016 could be found at https://github.com/AtmosIGFPAN/Hornsund_Data.

Competing interests. The authors declare that they have no conflict of interest.

Acknowledgements. Funding for this study was provided by the Ministry of Science and Higher Education, Republic of Poland, statutory activity no. 384 1/E-41/S/2017 and from the funds of the Leading National Research Centre (KNOW) received by the Centre for Polar Studies for the period 2014-2018. We are grateful to numerous dedicated individuals who have collected meteorological data over many decades.

Edited by: Paul Young

Reviewed by: three anonymous referees

\section{References}

Bais, A. F., McKenzie, R. L., Bernhard, G., Aucamp, P. J., Ilyas, M., Madronich, S., and Tourpali, K.: Ozone depletion and climate change: Impacts on UV radiation, Photochem. Photobiol. Sci., 14, 19-52, https://doi.org/10.1039/c4pp90032d, 2015.

Bernhard, G.: Trends of solar ultraviolet irradiance at Barrow, Alaska, and the effect of measurement uncertainties on trend detection, Atmos. Chem. Phys., 11, 13029-13045, https://doi.org/10.5194/acp-11-13029-2011, 2011.

Bernhard, G., Dahlback, A., Fioletov, V., Heikkilä, A., Johnsen, B., Koskela, T., Lakkala, K., and Svendby, T.: High levels of ultraviolet radiation observed by ground-based instruments below the 2011 Arctic ozone hole, Atmos. Chem. Phys., 13, 10573-10590, https://doi.org/10.5194/acp-13-10573-2013, 2013.

Bilbao, J., de Miguel, A, Mateos, D., and Román, R.: Long-term solar erythemal UV irradiance data reconstruction in Spain using a semiempirical method, J. Geophys. Res., 116, D22211, https://doi.org/10.1029/2011JD015836, 2011.

Boulton, C., Allison, L., and Lenton, T.: Early warning signals of Atlantic Meridional Overturning Circulation collapse in a fully coupled climate model, Nat. Commun., 5, 5752, https://doi.org/10.1038/ncomms6752, 2014.

Cleveland, W. S.: Robust locally weighted regression and smoothing, J. Am. Stat. Assoc., 74, 829-836, https://doi.org/10.2307/2286407, 1979.

Fioletov, V. E., Kerr, J. B., Wardle, D. I., Davies, J., Hare, E. W., McElroy, C. T., and Tarasick, D. W.: Long-term ozone decline over the Canadian Arctic to early 1997 from ground-based and balloon observations, Geophys. Res. Lett., 24, 2705-2708, https://doi.org/10.1029/97GL52829, 1997.

Garcia, R. R.: An Arctic ozone hole?, Nature, 478, 462-463, https://doi.org/10.1038/478462a, 2011.

Gurney, K. R.: Evidence for increasing ultraviolet irradiance at Point Barrow, Alaska, Geophys. Res. Lett., 25, 903-906, https://doi.org/10.1029/98GL00405, 1998.

Hessen, D. O. (Ed.): UV Radiation and Arctic Ecosystems, 321 pp., Springer-Verlag, New York, 2001.

Hülsen, G. and Gröbner, J.: Characterization and calibration of ultraviolet broadband radiometers measuring erythemally weighted irradiance, Appl. Opt., 46, 5877-5886, https://doi.org/10.1364/AO.46.005877, 2007.

IPCC (Intergovernmental Panel on Climate Change): Climate Change 2014 - Impacts, Adaptation and Vulnerability: Part B: Regional Aspects: Working Group II Contribution to the IPCC Fifth Assessment Report, Cambridge: Cambridge University Press, https://doi.org/10.1017/CBO9781107415386, 2014.

Junk, J., Feister, U., and Helbig, A.: Reconstruction of daily solar UV irradiation from 1893 to 2002 in Potsdam, Germany, Int. J. Biometeorol., 51, 505-512, https://doi.org/10.1007/s00484-0070089-4, 2007.

Koepke, P., De Backer, H., Bais, A., Curylo, A., Eerme, K., Feister, U., Johnsen, B., Junk, J., Kazantzidis, A., Krzyscin, J., Lindfors, A., Olseth, J., Den Outer, P., Pribullova, A., Schmalwieser, A., Slaper, H., Staiger, H., Verdebout, J., Vuilleumier, L., and Weihs, P.: Modelling solar UV radiation in the past: comparison of algorithms and input data, Proc. SPIE, 6362, Remote Sensing of Clouds and the Atmosphere, XI, https://doi.org/10.1117/12.687682, 2006.

Krzyścin, J. and Sobolewski, P.: The surface UV-B irradiation in the Arctic: observations at the Polish polar stations, Hornsund (77N,15E), 1996-1997, J. Atmos.-Sol. Terr. Phys., 63, 321-329, https://doi.org/10.1016/S1364-6826(00)00209-1, 2001.

Lindfors, A. V., Arola, A., Kaurola, J., Taalas, P., and Svenøe, T.: Long-term erythemal UV doses at Sodankylä estimated using total ozone, sunshine duration, and snow depth, J. Geophys. Res., 108, 4518, https://doi.org/10.1029/2002JD003325, 2003. 
Lindfors, A. and Vuilleumier, L.: Erythemal UV at Davos (Switzerland), 1926-2003, estimated using total ozone, sunshine duration, and snow depth, J. Geophys. Res Atmos., 110, D02104, https://doi.org/10.1029/2004JD005231, 2005.

Lindfors, A., Kaurola, J., Arola, A., Koskela, T., Lakkala, K., Josefsson, W., Olseth, J. A., and Johnsen, B.: A method for reconstruction of past UV radiation based on radiative transfer modeling: Applied to four stations in northern Europe, J. Geophys. Res., 112, D23201, https://doi.org/10.1029/2007JD008454, 2007.

Madronich, S.: UV radiation in the natural and perturbed atmosphere, in Environmental Effects of UV (Ultraviolet) Radiation, edited by: Tevini, M., Lewis Publisher, Boca Raton, 17-69, 1993.

McKinlay, A. F. and Diffey, B. L.: A reference action spectrum for ultraviolet induced erythema in human skin, in: Commission International de l'Éclairage (CIE), Res. Note, 6, 17-22, 1987.

Newman, P. A., Gleason, J. F., McPeters, R. D., and Stolarski, R. S.: Anomalously low ozone over the Arctic, Geophys. Res. Lett., 24, 2689-2692, https://doi.org/10.1029/97GL52831, 1997.

Rieder, H. E., Holawe, F., Simic, S., Blumthaler, M., Krzyścin, J. W., Wagner, J. E., Schmalwieser, A. W., and Weihs, P.: Reconstruction of erythemal UV-doses for two stations in Austria: a comparison between alpine and urban regions, Atmos. Chem. Phys., 8, 6309-6323, https://doi.org/10.5194/acp-8-6309-2008, 2008.
Sobolewski, P. and Krzyścin, J.: UV measurements at the Polish Polar station, Hornsund, calibration and data for the period 2005 2006, Publs. Inst. Geophys. Pol. Acad. Sci, D-67, 123-132, 2006.

Solar Backscatter Ultraviolet (SBUV) merged ozone data: ftp:// toms.gsfcnasa.gov/pub/sbuv/MERGED/, last access: 21 December 2017.

Taalas, P., Kaurola, J., Kylling, A., Shindell, D., Sausen, R., Dameris, M., Grewe, V., Herman, J., Damski, J., and Steil B.: The impact of greenhouse gases and halogenated species on future solar UV radiation doses, Geophys. Res. Lett., 27, 11271130, https://doi.org/10.1029/1999GL010886, 2000.

Tanskanen, A., Lindfors, A., Määttä, A., Krotkov, N., Herman, J., Kaurola, J., Koskela, T., Lakkala, K., Fioletov, V., Bernhard, G., McKenzie, R., Kondo, Y., O’Neill, M., Slaper, H., den Outer, P., Bais, A. F., and Tamminen, J.: Validation of daily erythemal doses from Ozone Monitoring Instrument with ground based UV measurement data, J. Geophys. Res., 112, D24S44, https://doi.org/10.1029/2007JD008830, 2007.

WMO (World meteorological Organization): Scientific Assessment of Ozone Depletion: 2014. Global Ozone Res. Monit. Proj. Rep., 55, 416 pp., Geneva, Switzerland, 2014. 